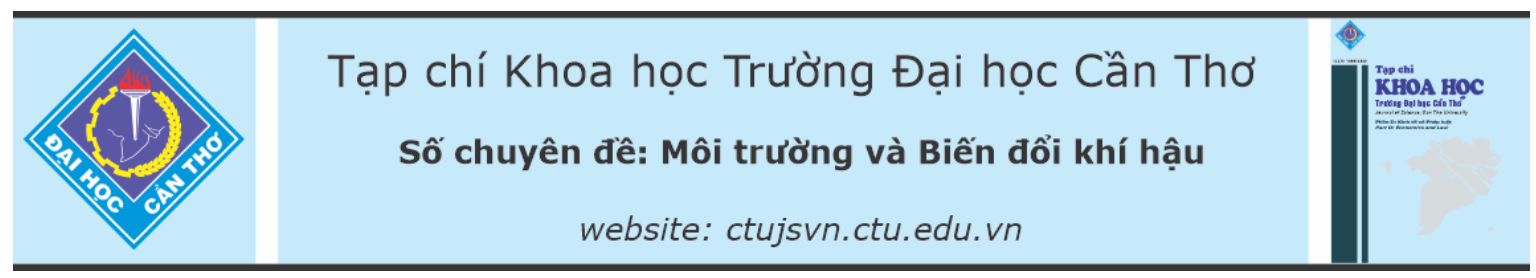

DOI:10.22144/ctu.jsi.2021.033

\title{
ĐÁNH GIÁ LÝ - HÓA TÍNH ĐẤT TRỒNG LÚA TRONG VÀ NGOÀI ĐÊ BAO KHÉP KÍN HUYỆN PHÚ TÂN, TỈNH AN GIANG
}

\author{
Trần Sỹ Nam*, Huỳnh Công Khánh, Huỳnh Văn Thảo và Nguyễn Công Thuận \\ Khoa Môi Truờng và Tài nguyên Thiên Nhiên - Truờng Đại học Cần Tho \\ *Nguoòi chịu trách nhiệm về bài viết: Trần Sỹ Nam (email: tsnam@ctu.edu.vn)
}

\section{Thông tin chung:}

Ngày nhận bài: $12 / 04 / 2021$

Ngày nhận bài sủa: 15/05/2021

Ngày duyệt đăng: 15/11/2021

\section{Title:}

Physical and chemical characteristics of soils inside and outside the full-dyke systems in Phu Tan district, An Giang province

\section{Tù khóa:}

Đê bao khép kin, đê bao lũng, hóa học đất, vật lý đất

\section{Keywords:}

Full-dyke system, semi-dyke system, soil chemical, soil physical

\begin{abstract}
This study was carried out in Phu Xuan and Hiep Xuong commune, Phu Tan district, An Giang province. The study aimed to evaluate characteristics of rice paddy soil quality between inside and outside of the full-dyke systems. Soil samples were collected at (i) 15 sites in the inside area of the full-dyke systems in 02/2018 and 10/2018, and (ii) 15 sites in the outside area of the full-dyke systems in 02/2018 and 8/2018. Soil samples were collected by the combination method with 5 sampling sites $(0-20 \mathrm{~cm})$ for analyzing the bulk density, density, porosity, soil texture, $p H, E C$, soil organic matter (SOM), cation exchange capacity (CEC), total nitrogen (TN), total phosphorus (TP), total potassium (TK), and nitrate $\left(\mathrm{NO}_{3}-\mathrm{N}\right)$. The results showed that $\mathrm{pH}$, density, bulk density, porosity, and soil texture were not significantly different between soil samples inside and outside the full-dyke systems, except EC value. The SOM, CEC, TN, and TP of soil samples inside the full-dyke system were higher than that of outside with the value of SOM (8.67\% and 5.49\%), CEC (26.1 $\mathrm{cmol} \mathrm{kg}^{-1}$ and $\left.20.7 \mathrm{cmol} \mathrm{kg}^{-1}\right), T N(0.32 \% \mathrm{~N}$ and $0.25 \% \mathrm{~N})$, and $\mathrm{TP}\left(0.19 \% \mathrm{P}_{2} \mathrm{O}_{5}\right.$ and $\left.0.14 \% \mathrm{P}_{2} \mathrm{O}_{5}\right)$, respectively. The $\mathrm{NO}_{3}-\mathrm{N}$ of soils samples were not significant different between inside (1.74 $\left.\mathrm{mg} \mathrm{kg}^{-1}\right)$ and outside $\left(1.52 \mathrm{mg} \mathrm{kg}^{-1}\right)$ the full-dyke systems ( $\left.p>0.05\right)$. Similarly, $\mathrm{TK}\left(\% \mathrm{~K}_{2} \mathrm{O}\right)$ were similar between soil samples inside and outside at $1.33 \% \mathrm{~K}_{2} \mathrm{O}$ and $1.32 \% \mathrm{~K}_{2} \mathrm{O}$, respectively. The result showed that SOM, TN, and TP soil samples inside were higher than that of outside the full-dyke system.
\end{abstract}

\section{TÓM TẮT}

Nghiên cưu được thực hiện tại xã Phú Xuân (khu vực trong đê bao khép kín) và Hiệp Xuoong (khu vực ngoài đê bao khép kín), huyện Phú Tân, tỉnh An Giang với mục tiêu đánh giá tinh chất đất giữa trong đê và ngoài đê bao khép kin. Mẫu đẩt được thu tại (i) 15 điểm trong đê với 2 đọt thu mẫu vào tháng 2/2018 và tháng 10/2018 và (ii) 15 điểm ngoài đê với 2 đọt thu mẫu vào tháng 2/2018 và tháng 8/2018. Mẫu đất được thu theo phuơng pháp tổ hợ gồm 5 mẫu đất (tầng $0-20 \mathrm{~cm}$ ) để phân tích dung trọng, tỷ trọng, độ xốp, sa cấu đất, $p H$, độ dẫn điện, chất hữu co, khả năng trao đổi cation (CEC), tồng đạm, tổng lân, tổng kali và nitrate $\left(\mathrm{NO}_{3}-\mathrm{N}\right)$. Kết quả nghiên cứu đã cho thấy $\mathrm{pH}$, dung trọng, tỷ trọng và độ xốp không có sự khác biệt giữa trong đê và ngoài đê, ngoại trù độ dần điện thì trong đê cao có ý nghĩa so với ngoài đê. Các thông số nhu hàm luợng chất hữu co, $C E C$, tổng đạm và tổng lân trong đê có giá trị cao hơn ngoài đê với các giá trị lần lươt: chất hữu co $(8,67 \%$ và $5,49 \%), C E C(26,1 \mathrm{cmol} \mathrm{kg}-$ ${ }^{1}$ và $\left.20,7 \mathrm{cmol} \mathrm{kg}^{-1}\right)$, tổng đạm $(0,32 \% \mathrm{~N}$ và $0,25 \% \mathrm{~N})$ và tổng lân $\left(0,19 \% \mathrm{P}_{2} \mathrm{O}_{5}\right.$ và $0,14 \% \mathrm{P}_{2} \mathrm{O}_{5}$ ). Thông số $\mathrm{NO}_{3}-\mathrm{N}$ cunng cho thấy được giá trị trong đê $\left(1,74 \mathrm{mg} \mathrm{kg}^{-1}\right)$ cao hon ngoài đê (1,52 $\left.\mathrm{mg} \mathrm{kg}^{-1}\right)$ nhung không có khác biệt ( $\left.p>0,05\right)$. Tương tư, hàm lương tổng kali không khác biệt giữa trong đê (1,33\%) và ngoài đê (1,32\%). Kết quả nghiên cúu cho thấy hàm lương chất hũu co, đạm, lân trong đê cao hơn ngoài đê. 


\section{GIỚI THIỆU}

An Giang là tỉnh đầu nguồn ở Đồng bằng sông Cửu Long, có dòng sông Tiền và sông Hậu chảy qua và chịu ảnh hưởng trực tiếp bởi lũ hàng năm (Võ Hồng Tú và ctv., 2012), mùa lũ thường kéo dài khoảng 6 tháng, bắt đầu từ tháng $7 / 8$ đến tháng 11/12 dương lịch. Dưới sự tác động của lũ, An Giang đã đẩy mạnh xây dựng các công trình thủy lợi phục vụ cho việc sản xuất nông nghiệp và đảm bảo an toàn cho người dân vùng lũ (Nguyễn Văn Thiệu \& Nguyễn Thị Ngọc Dung, 2014). Theo Chi cục Thủy Lợi An Giang (2013), toàn tỉnh có 623 tiểu vùng có tuyến đê bao kiểm soát lũ với tổng chiều dài là $5.372 \mathrm{~km}$ và bảo vệ hơn 240.000 ha cho sản xuất. Trong đó, đê bao triệt để có 397 tiểu vùng (kiểm soát lũ hơn 176.079 ha) và đê bao chống lũ tháng 8 có 224 tiểu vùng (kiểm soát lũ hơn 64.000 ha), riêng huyện Phú Tân có 22.123 ha (chiếm 12,56 \% trong toàn tỉnh) đất sản xuất nông nghiệp được bao đê triệt để và 100 ha được bao để chống lũ tháng 8 (chiếm $0,15 \%$ ). Dự án Bắc Vàm Nao ở huyện Phú Tân đã và đang phục vụ khá hiệu quả cho việc sản xuất, sinh hoạt của người dân trong vùng đê bao khép kín (Lê Anh Tuấn và ctv., 2015; Nguyễn Xuân Thịnh và ctv., 2016). Bên cạnh đó, đê bao khép kín đã góp phần bảo vệ mùa màng, tài sản, tạo điều kiện tốt cho chăn nuôi, cơ sở hạ tầng giao thông thuận lợi và tạo việc làm cho người dân (Bùi Thị Mai Phụng và ctv., 2017). Do nhu cầu thâm canh tăng vụ và mong muốn nâng cao sản lượng lúa nên nông dân đã và đang lạm dụng phân bón và sử dụng nông dược trong quá trình canh tác, đã gây ô nhiễm môi trường và ảnh hưởng đến sức khỏe con người (Lê Thanh Phong \& Hà Minh Tâm, 2015). Việc canh tác lúa 3 vụ thường xuyên trong vùng đê bao khép kín đã làm cho đất không được nhận phù sa hàng năm, dẫn đến đất dễ bị bạc màu và môi trường đất bị ô nhiễm (Dasgupta, 2005; Nguyễn Hiếu Trung, 2009). Nghiên cứu của Nguyễn Hữu Chiếm và ctv., (2017) ở 4 huyện của tỉnh An Giang đã cho thấy thành phần hóa học của đất trong đê có xu hướng cao hơn ngoài đề. Tuy nhiên, để có thêm cơ sở vững chắc trong việc đề xuất thời gian xả lũ phù hợp cho huyện Phú Tân và đánh giá hiện trạng lý hóa tính của đất trong và ngoài đê bao khép kín là thật sự cần thiết. Xuất phát từ những vấn đề trên, nghiên cứu "Đánh giá tính chất lý-hóa hoc của đất trồng lúa trong và ngoài đê bao khép kín huyện Phú Tân - tỉnh An Giang" đã được thực hiện.

\section{PHƯƠNG PHÁP NGHIÊN CÚU}

\subsection{Thời gian và địa điểm nghiên cứu}

Mẫu đất được thu 2 đợt trong năm 2018 tại xã Phú Xuân (khu vực trong đê bao khép kín) và xã Hiệp Xương (khu vực ngoài đê bao khép kín). Đợt 1 là tháng 02/2018 (sau khi thu hoạch lúa vụ Đông Xuân tại xã Phú Xuân và Hiệp Xương), đợt 2 là tháng 8/2018 tại xã Hiệp Xương (sau khi thu hoạch lúa vụ Hè Thu, do chỉ canh tác 2 vụ lúa/năm) và tháng 10/2018 tại xã Phú Xuân (sau khi thu hoạch lúa Thu Đông). Mẫu đất trong đê và ngoài đê được thu theo từng đợt, với tổng số cỡ mẫu được thu cho mỗi đợt là 15 mẫu trong đê và 15 mẫu ngoài đê. Tổng số mẫu là 60 mẫu. Các điểm thu mẫu được định vị bằng thiết bị định vị toàn cầu (Global Positioning System - GPS) và mẫu được thu lặp lại đúng vị trí lần thu mẫu đợt 2 . Vị trí các điểm thu mẫu được thể hiện trong Hình 1 .

\subsection{Phương pháp thu mẫu đất}

Dựa vào phương pháp thu mẫu đất của Nguyễn Hữu Chiếm và ctv. (2017), việc liên hệ và làm việc với chính quyền địa phương xã được thực hiện nhằm lựa chọn vị trí đại diện mang tính chất ngẫu nhiên, phù hợp để phục vụ trong quá trình nghiên cứu. Các bước thu mẫu đất được tóm lược như sau:

Bước 1: Dựa trên bản đồ hiện trạng sản xuất nông nghiệp của xã, 15 vị trí trong đê và 15 mẫu ngoài đê được chọn ngẫu nhiên để thu mẫu. Ngoài ra, thời gian thu mẫu phụ thuộc rất nhiều vào lịch thời vụ của từng xã, để xác định thời gian thu hoạch lúa vụ Đông Xuân và thời điểm trước khi mùa lũ bắt đầu ở ngoài đê.

Bước 2: Mẫu đất được thu ở tầng canh tác lúa $(0$ $-20 \mathrm{~cm}$ ) tại 5 vị trí trên từng thửa ruộng theo sơ đồ đường chéo (4 vị trí xung quanh và 01 vị trí trung tâm ruộng) với khối lượng gần như nhau, sau đó 5 mẫu đất được trộn lại thành 1 mẫu có khối lượng tương ứng $2 \mathrm{~kg}$. Mẫu sau khi thu được cho vào túi nylon, ghi ký hiệu mẫu, thời gian và địa điểm.

Bước 3: Sau khi thu xong, toàn bộ các mẫu đất được bảo quản và chuyển về phòng thí nghiệm Khoa Môi trường và Tài nguyên Thiên nhiên để tiến hành phơi khô ở nhiệt độ phòng. Riêng chỉ tiêu dung trọng được sấy khô $105^{\circ} \mathrm{C}$ đến trọng lượng không đổi.

Bước 4: Mẫu đất sau khi khô được nghiền nhỏ và cho qua rây có đường kính $\varphi=2 \mathrm{~mm}$ để phân tích các chỉ tiêu hóa, lý như $\mathrm{pH}$, độ dẫn điện (EC), chất hữu cơ $(\mathrm{CHC})$, tổng đạm $(\mathrm{TN})$, tổng lân (TP), tổng kali $(\mathrm{TK})$, nitrate $\left(\mathrm{NO}_{3}-\mathrm{N}\right)$ và khả năng trao đổi cation (CEC). 

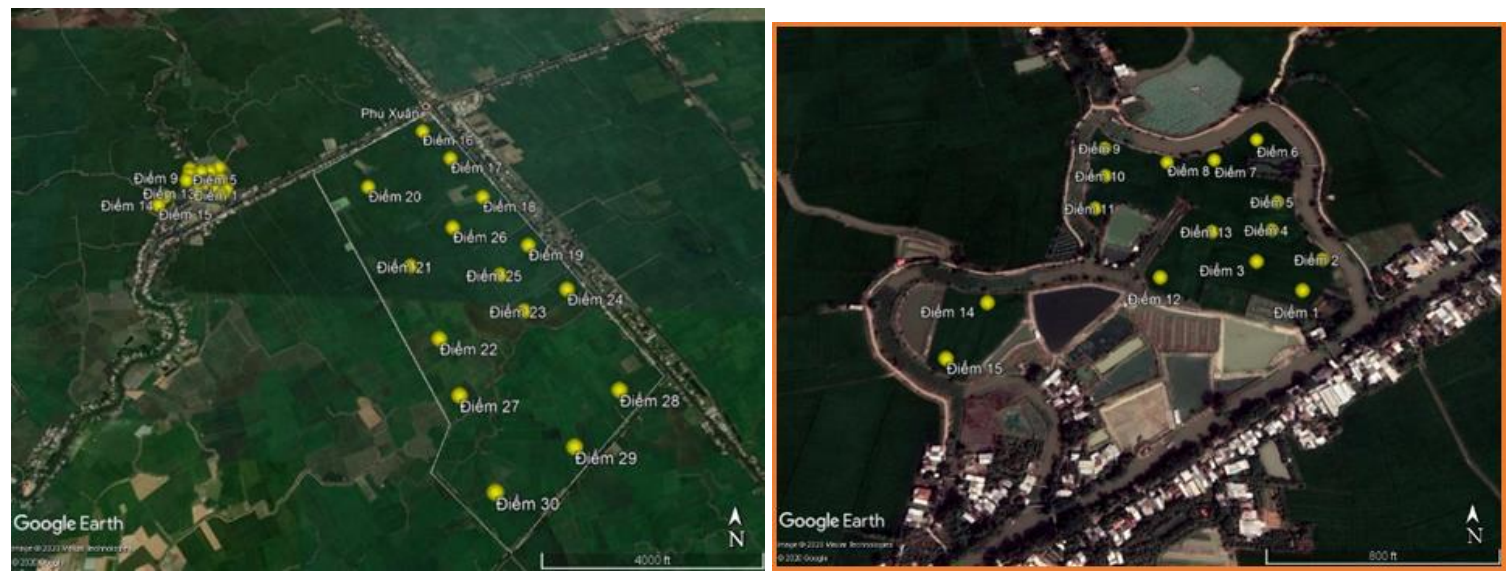

Hình 1. Bản đồ vị trí các điểm thu mẫu trong đê (trái) và ngoài đê (phải)

\subsection{Phương pháp phân tích mẫu}

Thành phần vật lý và hóa học của đất được phân tích theo các phương pháp hiện đang được áp dụng tại các phòng phân tích của Trường Đại học Cần Thơ (Bảng 1).

\section{Bảng 1. Phương pháp phân tích chỉ tiêu lý, hóa trong đất}

\begin{tabular}{|c|c|c|}
\hline Chỉ tiêu & Đơn vị & Phương pháp phân tích \\
\hline Dung trọng & $\mathrm{g} \mathrm{m}^{-3}$ & Xác định bằng ring với thể tích $100 \mathrm{~cm}^{3}$ \\
\hline Tỷ trọng & $\mathrm{g} \mathrm{m}^{-3}$ & Xác định bằng bình Pycnometer \\
\hline $\mathrm{pH}_{\mathrm{H} 2 \mathrm{O}}$ & & Trích bằng nước cất, tỉ lệ 1:5 (đất/nước), đo bằng máy TOA - Nhật \\
\hline EC & $\mathrm{mS} \mathrm{cm} \mathrm{cm}^{-1}$ & Trích bằng nước cất, tỉ lệ 1:5 (đất/nước), đo bằng máy Pioneer 30 \\
\hline $\mathrm{CHC}$ & $\% \mathrm{C}$ & $\begin{array}{l}\text { Phương pháp Walkley-Black: oxy hóa bằng } \mathrm{H}_{2} \mathrm{SO}_{4} \text { đđ }-\mathrm{K}_{2} \mathrm{Cr}_{2} \mathrm{O}_{7} \text {, chuấn độ } \\
\text { bằng FeSO4 0.1 N (TCVN 9294:2012) }\end{array}$ \\
\hline $\mathrm{TN}$ & $\% \mathrm{~N}$ & $\begin{array}{l}\text { Phương pháp Macro Kjeldahl. Chuẩn độ bằng } \mathrm{H}_{2} \mathrm{SO}_{4} \text { 0,1N (TCVN 6498:1999) } \\
\text { Vô cơ hóa bằng } \mathrm{H}_{2} \mathrm{SO}_{4} \text { đđ- }-\mathrm{HClO}_{4} \text {, hiện màu của phosphomolybdate với chất }\end{array}$ \\
\hline $\mathrm{TP}$ & $\% \mathrm{P}_{2} \mathrm{O}_{5}$ & $\begin{array}{l}\text { khử là ascorbic acid. So màu bằng máy quang phổ U2900 ở bước sóng } 880 \mathrm{~nm} \\
\text { (TCVN 8940:2011) }\end{array}$ \\
\hline TK & $\% \mathrm{~K}_{2} \mathrm{O}$ & $\begin{array}{l}\text { Trích bằng } \mathrm{BaCl}_{2} 0,1 \mathrm{M}, \mathrm{pH}=7.0 \text {. Đo trên máy hấp thu nguyên tử (TCVN } \\
8660: 2011 \text { ) }\end{array}$ \\
\hline CEC & $\mathrm{cmol} \mathrm{kg}^{-1}$ & Trích bằng $\mathrm{BaCl}_{2}$ 0,1M, chuẩn độ với EDTA 0,01M (TCVN 6646:2000) \\
\hline $\mathrm{NO}_{3}{ }^{-}$ & $\mathrm{mg} \mathrm{kg}^{-1}$ & Phương pháp khử hydrazine và so màu ở bước sóng $543 \mathrm{~nm}$. \\
\hline
\end{tabular}

\subsection{Phương pháp xử lý số liệu}

Số liệu được tính toán và xử lý bằng công cụ Microsoft Excel 2010, vẽ đồ thị bằng phần mềm Sigmaplot 10.0. Sử dụng phần mềm SPSS 13.0 kiểm tra tính đồng nhất của phương sai, kiểm tra phân phối chuẩn của dữ liệu bằng kiểm định Kolmogorov-smirnov, nếu dữ liệu không phân phối chuẩn thì sử dụng kiểm định Mann-Whitney Test để so sánh sự khác biệt giữa 2 mẫu độc lập trong và ngoài đê về các chỉ tiêu hóa học ở mức ý nghĩa $5 \%$.

\section{KÊT QUẢ VÀ THẢO LUẬN}

\subsection{Dung trọng, tỷ trọng và độ xốp}

Dung trọng đất trong đê có xu hướng cao hơn so với ngoài đê và khác biệt có ý nghĩa thống kê trong đợt $2(\mathrm{p}<0,05)$, với giá trị trung bình của 2 đợt thu mẫu dao động từ 1,02-1,04 $\mathrm{g} \mathrm{cm}^{-3}$ và được đánh giá là nhóm đất quá khô hay giàu chất hữu cơ (Karchinski, 1965 trích dẫn bởi Trần Thành Lập, 1999). Dung trọng đất là đặc tính quan trọng, có thể được sử dụng để đánh giá độ phì của đất về mặt vật lý như tình trạng nén dẽ, độ xốp hay tầng sâu mà rễ lúa có thể phát triển. Dung trọng đất ở Việt Nam thường dao động từ $0,7-1,7 \mathrm{~g} \mathrm{~cm}^{-3}$, nếu dung trọng đất $>1,2 \mathrm{~g} \mathrm{~cm}^{-3}$ thì việc canh tác rất khó khăn, năng suất cây trồng thường thấp do có nhiều sét, ít chất hữu cơ, làm ngăn cản sự phát triển của rễ (Nguyễn Thế Đặng \& Nguyễn Thế Hùng, 1999). Nghiên cứu của Nguyễn Hữu Chiếm và ctv. (2017) cũng cho thấy dung trọng đất trong và ngoài đê trung bình dao động từ 0,94 đển $0,95 \mathrm{~g} \mathrm{~cm}^{-3}$. Trong nghiên cứu này, dung trọng có xu hướng cao hơn nhưng không có sự chênh lệch lớn. 
Tỷ trọng của đất trong đê thấp hơn ngoài đê nhưng không có sự khác biệt ý nghĩa thống kê ( $\mathrm{p}>0,05)$, với giá trị trung bình trong đê dao động từ 2,08 đến $2,14 \mathrm{~g} \mathrm{~cm}^{-3}$ và ngoài đê dao động từ 2,14 đến $2,23 \mathrm{~g} \mathrm{~cm}^{-3}$. Độ xốp của đất cũng cho xu hướng trong đê thấp hơn ngoài đê với giá trị trung bình trong đê dao động từ 50,6 đến $51,1 \%$ và ngoài đê $55,1-59,3 \%$. Theo thang đánh giá của Karchinski (1965) trích dẫn bởi Trần Thành Lập (1999), đất trong và ngoài đê đều có tỉ trọng $<2,5 \mathrm{~g} \mathrm{~cm}^{-3}$ và được đánh giá có lượng mùn cao, điều đó là lý tưởng cho đất canh tác lúa (Miller, 1990). Đất có độ xốp cao là điều kiện tốt cho cây trồng phát triển và ngược lại đất kém thông thoáng có thể giới hạn sự phát triển của rễ (Lê Văn Khoa \& Nguyễn Văn Bé Tí, 2013). Nghiên cứu của Võ Thị Gương và ctv. (2004) đã cho thấy độ xốp của đất phù hợp cho sự phát triển của cây trồng từ $50 \%$. Như vậy, trong nghiên cứu này dung trọng, tỷ trọng và độ xốp của đất trong và ngoài đê đều phù hợp và thuận lợi cho canh tác lúa.

\section{Bảng 2. Dung trọng, tỷ trọng và độ xốp trong và ngoài đê bao khép kín}

\begin{tabular}{llrrr}
\hline Thời gian & Vị trí thu mẫu & Dung trọng $\left(\mathbf{g ~ c m}^{-3}\right)$ & Tỷ trọng $\left.\mathbf{~} \mathbf{g ~ c m}^{-3}\right)$ & Độ xốp (\%) \\
\hline \multirow{2}{*}{ Đợt 1} & Trong đê & $1,02 \mathrm{~ns} \pm 0,09$ & $2,08 \mathrm{~ns} \pm 0,15$ & $50,59 \mathrm{~ns} \pm 5,71$ \\
& Ngoài đê & $0,96 \mathrm{~ns} \pm 0,11$ & $2,14 \mathrm{~ns} \pm 0,17$ & $55,05 \mathrm{~ns} \pm 7,02$ \\
\hline \multirow{2}{*}{ Đợt 2} & Trong đê & $1,04 \mathrm{a} \pm 0,10$ & $2,14 \mathrm{~ns} \pm 0,16$ & $51,12 \mathrm{~b} \pm 4,20$ \\
& Ngoài đê & $0,90 \mathrm{~b} \pm 0,11$ & $2,23 \mathrm{~ns} \pm 0,15$ & $59,35 \mathrm{a} \pm 7,21$ \\
\hline
\end{tabular}

Số liệu được trình bày duoói dạng trung bình (TB) \pm độ lệch chuẩn (SD); cõ̃ mẫu $(n=15)$.

Trong cùng một cột (theo đợt), các số có chũ cái theo sau khác nhau thì có khác biệt ý nghĩa thống kê ở mức 5\% ( $p<0.05)$; ns là không khác biệt ý nghĩa thống kê.

\subsection{Trị số $\mathbf{p H} \mathrm{H}_{20}$ và $\mathrm{EC}$}

Trị số $\mathrm{pH}$ H2O trong đê đợt 1 thấp hơn so với ngoài đê với giá trị trung bình lần lượt tương ứng là 5,25 và 5,62 ; trong khi đó, trị số $\mathrm{pH}_{\mathrm{H} 2 \mathrm{O}}$ của đợt 2 trong đê cao hơn ngoài đê với giá trị trung bình trong đê 5,40 và ngoài đê 4,93 . Như vậy, trong nghiên cứu

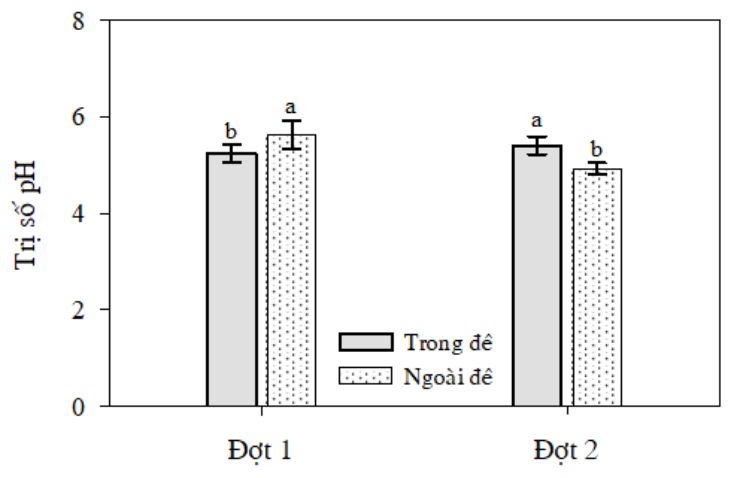

này trị số $\mathrm{pH}_{\mathrm{H} 2 \mathrm{O}}$ không có sự chênh lệch rõ rệt, điều đó cho thấy sự ảnh hưởng của hệ thống đê bao khép kín đến trị số $\mathrm{pH}$ là chưa đáng kể. Theo thang đánh giá của Vũ Cao Thái (1997), đất khu vực trong đê và ngoài đê được đánh giá là đất phèn yếu với trị số $\mathrm{pH}_{\mathrm{H} 2 \mathrm{O}}$ trong khoảng 4,5-5,5.

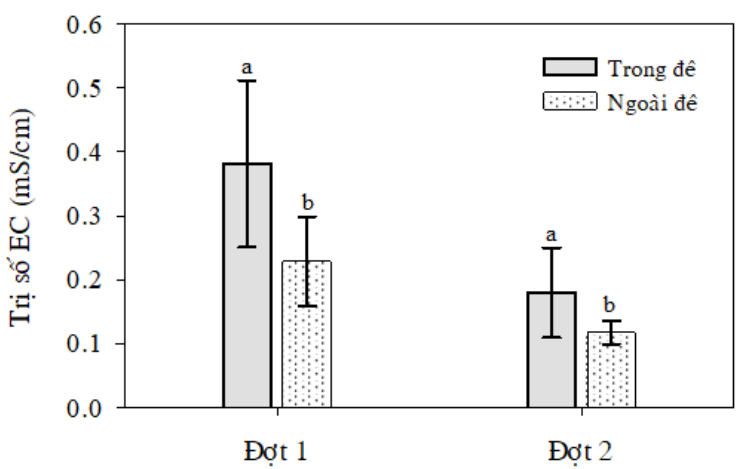

Hình 2. Trị số pHH2O và $\mathrm{EC}$ trong và ngoài đê

Ghi chú: Số liệu được trình bày dưới dạng $T B \pm S D$, cõ mẫu n = 15; trong cùng một đọt, các cột có các chũ cái khác nhau thì khác biệt có ý nghĩa thống kê ở mức 5\%.

Kết quả nghiên cứu cho thấy trị số EC trong đê có xu hướng cao hơn ngoài đê và khác biệt có ý nghĩa về mặt thống kê tại 2 đợt thu mẫu $(\mathrm{p}<0,05)$. Nguyên nhân có thể là do đất khu vực ngoài đê thường xuyên bị ngập khô xen kẽ và có sự thoát nước, điều đó đã làm đất bị rửa trôi liên tục, nên trị số EC có xu hướng giảm và thấp hơn so với khu vực trong đê. Trị số $\mathrm{EC}$ trong nghiên cứu này cũng tương đồng với kết quả nghiên cứu của Nguyễn Hữu
Chiếm và ctv. (2017) và trị số $\mathrm{EC}<0,4 \mathrm{mS} \mathrm{cm}^{-1}$ nên không ảnh hưởng đến sự phát triển cây trồng ( $\mathrm{Ngô}$ Ngọc Hưng, 2004).

\subsection{Hàm lượng chất hữu cơ và khả năng trao đổi cation}

Hàm lượng chất hữu cơ và khả năng trao đổi cation của khu vực trong đê cao hơn ngoài đê và có sự khác biệt ý nghĩa $(\mathrm{p}<0,05)$. Cụ thể, hàm lượng trung bình chất hữu cơ trong đê dao động từ 8,5 đến 
$8,83 \%$ và ngoài đê từ 5,11 đến $5,86 \%$. Theo thang đánh giá của Chiurin (1972) trích dẫn bởi Ngô Ngọc Hưng (2004), hàm lượng chất hữu cơ trong đê được đánh giá từ khá đến giàu, trong khi ngoài đê thì được đánh giá từ trung bình đến khá. Theo Nguyễn Hữu Chiếm và ctv. (2017), nguyên nhân dẫn đến sự chênh lệch về hàm lượng chất hữu cơ trong và ngoài đê là do nông dân trong đê đã sử dụng nhiều đạm và lân, điều đó đã làm cho sinh khối tảo tăng lên và tích tụ lại trong đất. Bên cạnh đó, sự tích tụ của rễ lúa trong thời gian dài cũng là nguyên nhân dẫn đến hàm lượng chất hữu cơ cao.
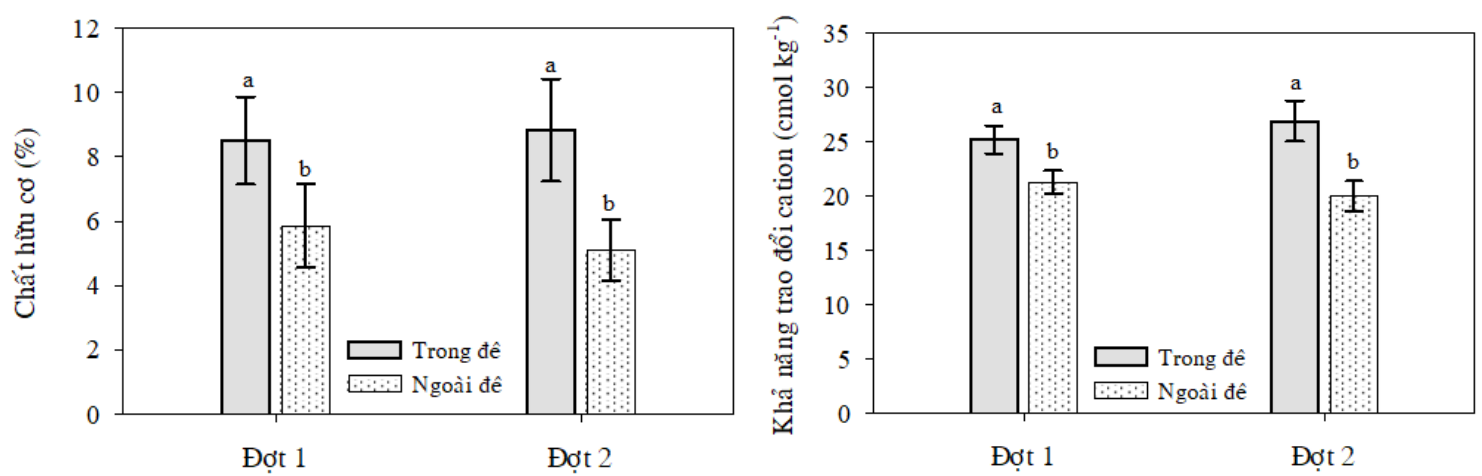

Hình 3. Hàm lượng $\mathrm{CHC}$ và $\mathrm{CEC}$ trong và ngoài đê

Ghi chú: Số liệu được trình bày dưới dạng $T B \pm S D$, cỡ mẫu $n=15$; trong cùng một đột, các cột có chũ cái khác nhau thì khác biệt có ý nghĩa thống kê ở mức 5\%.

Khả năng trao đổi cation của đất tùy thuộc vào nhiều yếu tố như thành phần khoáng sét, hàm lượng chất hữu cơ và $\mathrm{pH}$ của đất. Kết quả nghiên cứu cho thấy khả năng trao đổi cation trong đê có giá trị trung bình dao động từ 25,2 đến $26,9 \mathrm{cmol} \mathrm{kg}^{-1}$ và ngoài đê là $20,0-21,3 \mathrm{cmol} \mathrm{kg}^{-1}$ và có sự khác biệt ý nghĩa về mặt thống kê $(\mathrm{p}<0,05)$. Nguyên nhân dần đến chỉ số CEC trong đê cao là do hàm lượng chất hữu cơ và dinh dưỡng của đất trong đê cao hơn ngoài đê. Theo thang đánh giá của Landon (1984) trích dẫn bởi Ngô Ngọc Hưng (2004), khả năng trao đổi cation khu vực trong đê và ngoài đê được đánh giá ở mức cao và hàm lượng trong khoảng15,1-30,0 $\mathrm{cmol} \mathrm{kg}^{-1}$.

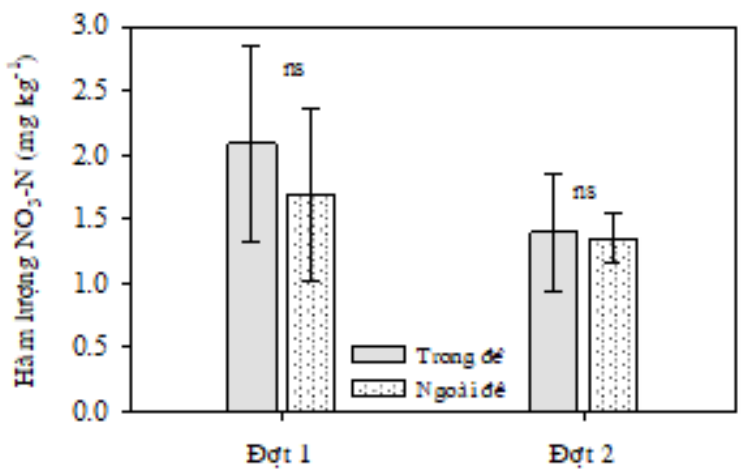

\subsection{Hàm lượng đạm nitrate và tổng đạm}

Hàm lượng đạm nitrate trung bình trong đê từ $1,4-2,2 \mathrm{mg} \mathrm{kg}^{-1}$, ngoài đê từ $1.3-1.7 \mathrm{mg} \mathrm{kg}^{-1}$, mặc dù hàm lượng nitrate trong đê cao hơn ngoài đê nhưng không có sự khác biệt ý nghĩa $(\mathrm{p}<0,05)$. Theo thang đánh giá của Agricultural Compendium (1989), hàm lượng đạm $\mathrm{NO}_{3}-\mathrm{N}$ ở mức thấp $\left(<5 \mathrm{mg} \mathrm{kg}^{-1}\right)$. Kết quả trong nghiên cứu này cũng phù hợp và không chênh lệch nhiều so với một số nghiên cứu trước đó tại huyện Phú Tân (Dương Hồng Gấm, 2015; Nguyễn Hữu Chiếm và ctv., 2017).

Hình 4. Hàm lượng đạm nitrate và tổng đạm trong và ngoài đê

Ghi chú: Số liệu được trình bày dưới dạng $T B \pm S D$, cõ̃ mẫu $n=15$; trong cùng một đọt, các cột có các chũ cái khác nhau thi khác biệt có ý nghĩa thống kê ở múc 5\%; ns là không khác biệt ý nghĩa thống kê. 
Hàm lượng đạm tổng số trong đê cao hơn ngoài đê và khác biệt có ý nghĩa thống kê $(\mathrm{p}<0,05)$, so với thang đánh giá của Kyuma (1976) thì TN trong và ngoài đê được đánh giá ở mức giàu với giá trị trong đê $0,32-0,33 \%$ và ngoài đê $0,23-0,26 \%$, cả 2 đợt thu mẫu đều lớn hơn $0,2 \%$. Kết quả nghiên cứu của Huỳnh Thanh Đức (2014) đã cho thấy lượng phân đạm sử dụng trong đê cao hơn ngoài đê với khối lượng lần lượt là $125 \mathrm{kgN} \mathrm{ha}^{-1} \mathrm{vụ̣}^{-1}$ (tương ứng 375 ha $^{-1}$ năm$^{-1}$ ) và $113 \mathrm{kgN} \mathrm{ha}^{-1} \mathrm{vụ}^{-1}$ (tương ứng $226 \mathrm{kgN}$ ha $^{-1}$ năm $^{-1}$, do ngoài đê chỉ trồng có 2 vụ lúa/năm). Sự chênh lệch về khối lượng phân bón đã dẫn đến hàm lượng tổng đạm trong đất tăng cao hơn so với ngoài đê và điều đó cũng là nguyên nhân dẫn đến hàm lượng đạm $\mathrm{NO}_{3}-\mathrm{N}$ trong đê cao hơn ngoài đê.

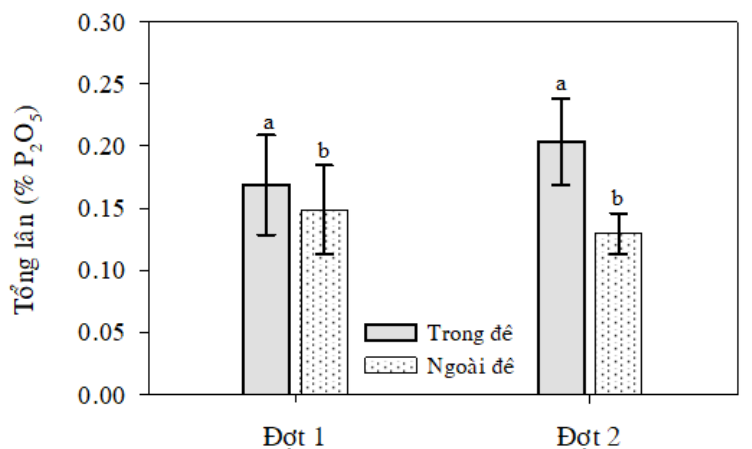

\subsection{Hàm lượng tổng lân và tổng kali}

Hàm lượng TP trong đê cao hơn ngoài đê và khác biệt có ý nghĩa $(\mathrm{p}<0,05)$, với giá trị TP trong đê từ 0,17 đến $0,21 \% \mathrm{P}_{2} \mathrm{O}_{5}$ và ngoài đê $0,13-0,15$ $\% \mathrm{P}_{2} \mathrm{O}_{5}$. Nguyên nhân dẫn đến sự khác biệt về TP trong và ngoài đê có thể là do lượng phân lân đã sử dụng trong đê cao hơn so với ngoài đê với kết quả nghiên cứu của Huỳnh Thanh Đức (2014) cho thấy trong đê $89 \mathrm{~kg} \mathrm{ha}^{-1} \mathrm{vụ}^{-1}$ (tương ứng $267 \mathrm{~kg} \mathrm{ha}^{-1}$ năm 1) và ngoài đê $70 \mathrm{~kg} \mathrm{ha}^{-1} \mathrm{vụ}^{-1}$ (tương ứng $140 \mathrm{~kg} \mathrm{ha}^{-}$ ${ }^{1}$ năm $\left.^{-1}\right)$. Khi so sánh với thang đánh giá của Lê Văn Căn (1978) thì đất khu vực nghiên cứu là đất giàu lân $\left(>0,13 \mathrm{P}_{2} \mathrm{O}_{5}\right)$.

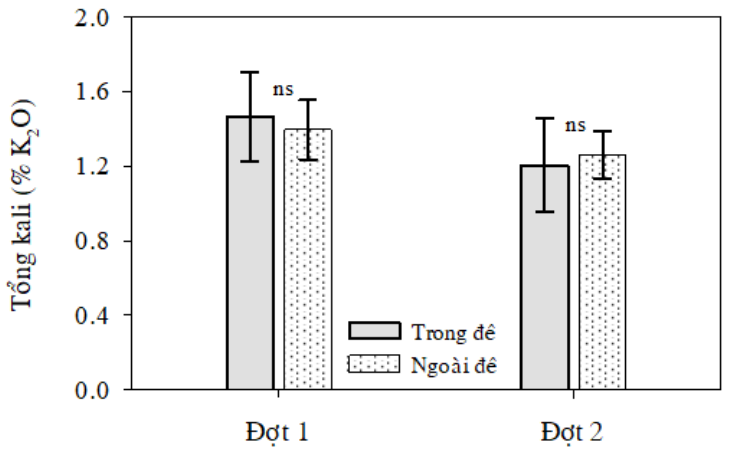

Hình 5. Hàm lượng tổng lân và tổng kali trong và ngoài đê

Ghi chú: Số liệu đuợc trình bày duới dạng $T B \pm S D$, cõ̃ mẫu $n=15$; trong cùng môt đọt, các cột có các chũ cái khác nhau thì khác biệt có ý nghĩa thống kê ở mức 5\%; ns là không khác biệt ý nghĩa thống kê.

Hàm lượng $\mathrm{TK}$ trong và ngoài đê có giá trị dao động từ $1,20-1,46 \% \mathrm{~K}_{2} \mathrm{O}$ và $1,26-1,40 \% \mathrm{~K}_{2} \mathrm{O}$, không có sự khác biệt về mặt thống kê $(\mathrm{p}>0,05)$. So với thang đánh giá của Kyuma (1976) thì hàm lượng tổng kali ở mức trung bình. Một trong những nguyên nhân dẫn đến hàm lượng $\mathrm{TK}$, không có sự khác biệt giữa trong và ngoài đê là do lượng phân kali sử dụng bón cho đất gần như nhau giữa 2 địa điểm, cụ thể trong đê là $52 \mathrm{~kg} \mathrm{ha}^{-1}$ vụ̣ và ngoài đê $48 \mathrm{~kg} \mathrm{ha}^{-1} \mathrm{vụ}$ 1 (Huỳnh Thanh Đức, 2014).

\section{KẾT LUẬN}

\subsection{Kết luận}

Kết quả cho thấy đê bao khép kín tại điểm nghiên cứu đã có ảnh hưởng đến một số chỉ tiêu về chất lượng đất trồng lúa. Các thông số dung trọng, tỷ trọng và độ xốp trong và ngoài đê không có chênh lệch đáng kể. Sự khác biệt về $\mathrm{pH}$ của đất ở trong và ngoài đê không thấy rõ diễn biến, nhưng EC trong đê cao hơn ngoài đê ở cả 2 thời điểm thu mẫu.
Các thông số hóa học như chất hữu cơ, $\mathrm{CEC}$, tổng đạm và tổng lân trong đê cao hơn và khác biệt có ý nghĩa so với ngoài đê,--trong khi đó thông số $\mathrm{NO}_{3}-\mathrm{N}$ và $\mathrm{TK}$ không có sự khác biệt.

\subsection{Kiến nghị}

Cần nghiên cứu về tác động của đê bao khép kín đến khía cạnh về sự tồn lưu thuốc bảo vệ thực vật trong đất và tính đa dạng sinh học của côn trùng trong đất.

\section{LÒ̀I CẢM TẠ}

Đề tài này được tài trợ bởi Dự án Nâng cấp Trường Đại học Cần Thơ VN14-P6 bằng nguồn vốn vay ODA-E3 từ chính phủ Nhật Bản.

\section{TÀI LIỆU THAM KHẢO}

Agricultural Copendium. (1989). Land use, land cover and soil sciences - Vol IV - Management of Agricultural Land: Chemical and Fertility Aspects.

Bùi Thị Mai Phụng, Huỳnh Công Khánh, Phạm Văn Toàn \& Nguyễn Hữu Chiếm. (2017). Đánh giá 
khối lượng bồi tích và thành phần dinh dưỡng của phù sa trong và ngoài đê bao khép kín ở tỉnh An Giang. Tạp chí Khoa hoc Truòng Đại học Cần Tho, Số chuyên đề: Môi truờng và Biến đổi khi hậu, 1, 146-152..

Chi Cục Thủy Lợi An Giang. (2013). Tổng điều tra đánh giá hiện trạng hệ thống công trình thủy lợi tinh An Giang.

Dasgupta, S., Meisner, C., Wheeler, D., Nhan, L.T., \& Khuc, X. (2005). Pesticide poisoning of farm workers: implications of blood test results from Vietnam. World Bank Policy Research Working Paper.

Dương Hồng Gấm. (2015). Đánh giá chất luợng đất và phù sa trong và ngoài đê bao ở Chơ Móri và Phú Tân tỉnh An Giang (Luận văn thạc sĩ). Trường Đại học Cần Thơ.

Huỳnh Thanh Đức. (2014). Đánh giá hiện trạng sản xuất lúa trong và ngoài đê bao khép kín tại tỉnh An Giang (Luận văn thạc sĩ). Trường Đại học Cần Thơ

Kyuma, K. (1976). Paddy soils in the Mekong Delta of Vietnam. The center for Southeast Asian Studies, Kyoto University, Kyoto.

Lê Anh Tuấn, Huỳnh Vương Thu Minh, Đinh Diệp Anh Tuấn \& Nguyễn Thị Phương Thảo. (2015). Nghiên cứu co sở cho Dự án Quản lý nước dụa vào cộng đồng (CWMPs). OXFAM - DRAGON - WARECOD, Dự án Inclusion/Chương trình Quản lý Nước Mekong, Việt Nam.

Lê Thanh Phong \& Hà Minh Tâm. (2015). Ảnh hưởng môi trường của ba mô hình canh tác lúa cánh đồng mẫu lớn, GAP và truyền thống ở Đồng bằng sông Cửu Long. Tap chi Khoa hoc Truờng Đại hoc C Cần Tho: Số chuyên đề: Nông nghiẹp, Thủy sản và Công nghệ Sinh họ, 38, 64-75.

Lê Văn Căn. (1978). Giáo trình Nông Hóa. Nhà xuất bản Nông nghiệp Hà Nội

Lê Văn Khoa \& Nguyễn Văn Bé Tí. (2013). Phân cấp độ bền và các yếu tố ảnh hưởng đến độ bền cấu trúc đất của nhóm đất phù sa vùng Đồng Bằng sông Cửu Long, Việt Nam. Tạp chí khoa hoc Truờng Đại hoc Cần Tho: Số chuyên đề: Nông nghiệp, Thủy sản và Công nghệ Sinh học, 26, 219-226.

Miller, R. W. (1990). Soils: An introduction to soils and plant growth, Sixth edition. Prentice - Hall
International Edition. Part: Soil physical and soilwater properties

Ngô Ngọc Hưng. (2004). Giáo trình thực tập thổ nhữ̛ng. Trường Đại học Cần Thơ.

Nguyễn Hiếu Trung. (2009). Khả năng thích ưng của người dân trong các vùng đê bao chống lũ $Đ B S C L$. Báo cáo trong Dự án nghiên cứu "Assessment of adaptation capacity to floods in the Mekong Delta" với M-POWER, Thái Lan.

Nguyễn Hữu Chiếm, Huỳnh Công Khánh, Nguyễn Xuân Lộc \& Đinh Thị Việt Huỳnh. (2017). Đánh giá và so sánh tính chất lý-hóa học đất trồng lúa trong và ngoài đê bao khép kín tỉnh An Giang. Tạp chi Khoa học Truòng Đại hoc Cần Tho: Số chuyên đề: Môi trương và Biến đổi khi hậu, 1 , 86-92.

Nguyễn Thế Đặng \& Nguyễn Thế Hùng. (1999). Giáo trình đất. NXB Nông nghiệp, Hà Nội.

Nguyễn Văn Thiệu \& Nguyễn Thị Ngọc Dung. (2014). Yếu tố ảnh hưởng đến sinh kế và giải pháp sinh kế bền vững cho người dân vùng lũ tỉnh An Giang. Tạp chi Khoa hoc Truòng Đại hoc Cần Tho: Số chuyên đề: Khoa hoc Chính trị, Kinh tế và Pháp luật, 31, 39-45.

Nguyễn Xuân Thịnh, Trương Thanh Tân, Trần Thị Lệ Hằng \& Văn Phạm Đăng Trí. (2016). Đánh giá tổng hợp hiệu quả dự án kiểm soát lũ Đồng bằng sông Cửu Long - Điểm nghiên cứu Nam Vàm Nao. Tap chi Khoa hoc Công nghệ Nông nghiệp Việt Nam, 5(66), 95-102.

Trần Thành Lập (1999). Phì nhiêu đất. Bài giảng phì nhiêu đất và phân bón. Đại học Cần Thơ.

Võ Hồng Tú, Nguyễn Duy Cần, Nguyễn Thùy Trang \& Lê Văn An. (2012). Tính tổn thương sinh kế nông hộ bị ảnh hưởng lũ tại tỉnh An Giang và các giải pháp ứng phó. Tạp chí Khoa hoc Truòng Đại hoc Cần Tho, 22b, 294-303.

Võ Thị Gương. (2004). Báo cáo kết quả nghiên cúu đề tài nghiên cúu khoa hoc công nghẹ đánh giá chất luợng đất-nuớc và đề xuất biện pháp sư dụng đất thích hơp cho mô hình canh tác lúa tôm tại huyện Mỹ Xuyên tỉnh Sóc Trăng. Khoa Nông nghiệp và SHUD. Trường Đại học Cần Thơ.

Vũ Cao Thái. (1997). Quan hệ độ phì nhiêu đất, phân bón, năng suất lúa trên một số loại đất ĐBSCL. Nông nghiệp và Tài nguyên đất sử dụng phân tại Việt Nam. NXB TP. Hồ Chí Minh. 